\title{
Listening space: some lessons from some artists with and without learning disabilities and their art materials
}

\section{Authors}

Hannah Macpherson and Alice Fox

University of Brighton, Brighton, UK

\author{
Susan Street, John Cull, Tina Jenner, Des Lake, Martyn Lake \\ and Shirley Hart \\ Rocket Artists
}

\section{Introduction}

"Art activities are not just helping you to be with a person they are helping you to find a shared language and have something to say back to that person which reaches them. Done well they involve an attentive 'being-with' that often feels like a conversation but without words - a form of artful listening so that you can respond in a format that is appropriate and meaningful to that person." (AF, Inclusive Artist)

In this paper we reflect on the embodied and material geographies of listening through creative visual arts activities with people with learning disabilities. The paper has been developed through our recorded conversations (as an Inclusive Artist and a Social and Cultural Geographer) and through working alongside the contemporary arts group 'The Rockets' who have learning disabilities. The rationale for focusing on listening is threefold; firstly, there is a growing interest in how art materials, from paint to photographs, can give and create voice (Askins and Pain 2011; Tolia-Kelly 2007; Palmer and Jones 2014). However, while some consideration has been given to the embodied experiences of installation art (Hawkins 2010) and the potential qualities of art-geography collaborations (Foster and Lorimer 2007), the ways in which art materials themselves become involved in a process of 'giving voice' and the 
specific ways we need to listen in order to hear what is being said through an artwork is relatively under-explored in the discipline of Geography. Secondly, we feel an expanded conception of listening (as a form of being-with and responding to a person) accurately describes a significant portion of AF's Inclusive arts practice with the Rockets - illustrated in the quote above and expanded upon in our discussion.

Thirdly, when working with people who are non-verbal, have distinctive communicative styles or have complex communication needs, art and performance have been shown to be a particularly useful way of bringing these people together and aiding communication (Boxall and Ralph 2011; Hall 2013). These points are discussed in more depth through the paper.

\section{Arts based methods of listening}

A growing number of researchers are turning to visual arts methodologies as a way of conducting research, presenting research papers in innovative formats and engaging marginalized communities (Askins and Pain 2011; Leavy 2009; Tolia-Kelly 2007). This builds on a long tradition in community development of using art as a method of participant self-representation (White 2009) and is in part as a reaction to critiques of the limitations of transcripts (Crang 2005; Dewsbury 2009; Harrison 2007) and in part is driven by a concern to enhance research impact beyond the academy (Macpherson, Hart and Heaver 2014). Prior research using visual and performance art methodologies in geography praise these techniques for their capacity to give voice to marginalized groups, disrupt traditional research power hierarchies and facilitate multi-sensory modes of research dialogue (Butler 2006; Pratt and Johnston 2010; Tolia-Kelly 2007). For example, Askins and Pain (2011) argue that ' ...materialbased hands-on methods can be effective tools enabling people to speak without 
necessarily using their voices.' (Askins and Pain 2011, p186). While Tolia-Kelly (2007) writes that art '....attempt (s) to capture alternative vocabularies and visual grammars that are not always encountered or expressible in oral interviews' (p135, also cited in Askins and Pain 2011 p807).

Visual and performative practices of listening are particularly important modes of research communication and self expression in the case of people with learning disabilities, some of whom are non-verbal, have distinctive communicative styles or are simply unused to being listened to (Brookes et al. 2012; Hyden and Antelius 2010; Nind 2008). For example, Hall (2013) in his work on creative arts activities with people with learning disabilities builds on such observations and argues such activities '...provide opportunities for embodied and emotional expression' (p244). However, limited attention has been given to how such forms of expression occur through particular art materials or what sorts of art materials, facilitation techniques and listening practices are required in order for the voices of people with learning disabilities to be heard efectively.

In fact a number of accounts of arts methodologies have begun to reflect critically on their capacity to enable voice. It has been acknowledged that art materials and activities can work both with and against research questions - obscuring as well as revealing certain answers and disabling as well as enabling certain channels of communication (Askins and Pain 2011; Parr 2006). Furthermore, research has begun to point towards the way in which creative processes do not simply 'give voice' to pre-existing opinions and identities but rather inject the non-human agency of particular art materials into a situation that involves creating voice and meaning 
(Hawkins 2011; Macpherson and Bleasedale 2012). This raises unanswered questions about exactly what is being listening to when the research encounter involves arts activities. For example, while Gauntlett (2006) argues that the benefit of art materials in social research is that they allow time for a more considered answer to a question than a verbal question and answer format. A more in depth consideration of how particular art materials 'speak-with' people in different ways is required. Askins and Pain's (2011) work on the 'messy materialities' of creative arts activities begins to point to this issue when they conclude that ' $\ldots$..there is a need to connect understandings of creative arts methodologies with current debates on materiality, to interrogate more closely how participation may be dis/enabled...' (p817)

\section{Methodology: observation, involvement and conversation}

This research paper is developed from a dialogue with Inclusive Arts Practitioner AF and the contemporary arts group 'The Rockets'. It was driven by the question: What can be learnt about listening through arts materials from Inclusive Artist AF and the group 'The Rockets'? The paper has been developed from a set of recorded conversations with the co-author AF and our participant observation, pictures and auto-ethnographic reflection from a series of Inclusive arts workshops in 2013 with the Rocket artists. The Rocket artists consist of twelve artists with learning disabilities and their collaborators and was established in 2002 funded by Arts Council England, South East and based at the Phoenix Artists Studios in Brighton. The Rocket artists work in collaboration with University of Brighton arts students and have exhibited at galleries including Tate Modern, the Royal Festival Hall and Pallant House. The term Inclusive arts is used by AF to describe creative collaborations between learning disabled and non-learning disabled artists. This process is designed to support a 
mutually beneficial two-way creative exchange that enables the artists to share an artistic journey, learn (and un-learn) from each other. This process attempts to place the non-disabled artists in the more radical role of collaborator and proposes a shift away from the traditional notion of 'worthy helper'. Through re-defining this role and shedding the notion of the 'expert' artist AF acknowledges the valuable and skillful contribution that artists with learning disabilities can bring to the arts. Such modes of working differ from some studios who work with individual artists with learning disabilities to brand their individual work or from the majority of day centre arts environments for people with learning disabilities who tend to use art activities as 'time fillers'.

AF has worked alongside the Rockets for over twelve years. The timescale of her involvement has been crucial in developing meaningful dialogue and means she has a very significant body of accumulated expertise which she has been willing to share in conversation for this paper. This has been important for the development of this research and helps us avoid any accusation of exploitation (see Nind 2008). Geographers who work alongside artists can be pushed to question their conventions and working practices (Foster and Lorimer 2007). As a Geographer I certainly have developed an enhanced appreciation of the skillful practice of arts based communication. Writing this paper has also involved AF shuttling between her role as an Inclusive artist and her role as a co-author. In fact talking about these arts activities together has involved its own forms of artistry and skill. Before logical sentences were strung together for the purposes of this paper a much messier interaction occurred as part of what Worth and Poynor (2011) refer to as “...the pleasurable struggle of attempting to 'draw' the processes of creative practice with words." (p149) 
We have found it difficult to capture fully the texture and complexity of a creative session with the Rockets in this paper. However, we hope the combination of images and ideas that we present here give the reader a sense of the forms of practice that occurred in the studio. We have organized the paper into a series of sections. Firstly, we discuss some of the specific contextual background to listening to the voices of people with learning disabilities in the United Kingdom. Then we explore some of the ways in which the art activities of the Rockets involve embodied and material forms of listening. Specifically we address the following themes; the ways in which the studio space and materials are set up in order to be a conducive space for listening; how particular art materials are selected which are appropriate for giving voice; how certain art practices and materials can offer non-verbal 'meeting points' between people and how time and expertise is required to recognize when people are not saying much at all in their art work (through cliché, repetition, fear or absence).

\section{Listening to people with learning disabilities}

A range of social, economic and corporeal forces have worked to constrain the voices of people with learning disabilities in the United Kingdom over the past two centuries (Nind 2008). In the first half of the twentieth century statistical diagnostic procedures derived from medical and psychological research produced the category 'learning disability' and 'mentally deficient' and were utilized as evidence for the need to institutionalize people away from free society (Radford 1994). While most people with learning disabilities in the United Kingdom now live in community settings, rather than in institutions, they remain among the most disadvantaged in our society. Prior research has revealed the ways in which people with learning disabilities often 
have a very limited say over the direction and nature of their own lives (Hall 2011; Nind 2008). It has also been observed that many people with learning disabilities who participate in research may be reluctant to express their genuine views or opinions for fear of repercussions (Nind 2008). For example, they may have had bad experiences of education establishments or previous experiences of abuse of their human rights (JCHR 2008). In early academic research there is clear historical evidence of the abuse and exploitation of people with learning disabilities who were used as subjects of medical testing (Carlson 2010). In fact it was not until the 1980s that any room was made for their voices to be heard within research and evaluations of the services they received (Kiernan, 1999). Recent estimates from the Department of Health estimate that 65,000 children and 145,000 English adults have severe or profound learning disabilities, and 1.2 million have mild or moderate learning disabilities (Department of Health 2009, Valuing People). It is argues that well facilitated arts activities and the use of visual methods can help those people express themselves and exercise a degree of choice over their lives (Reynolds 2002; Boxall and Ralph 2011). However, sadly, for those individuals who live in specialist residential homes recent research reveals that there are continuing problems with accessing mainstream or community creative leisure activities outside those residential environments (Reynolds, 2002).

In recent years all sorts of creative strategies have been used to engage people with learning disabilities in research and help them have a say over their own lives, including video diaries, picture question and answers, storytelling and forum theatre (Brookes et al. 2012). Some people with severe and profound learning disabilities are primarily non-verbal (including some members of the Rockets). However, even amongst those born deaf-blind prior research has shown that sophisticated forms of 
communication between parent and child are developed which enable the child to have a voice and feel listened to (Goode, 1995). Inclusive arts practitioners are encouraged to develop a sophisticated set of listening techniques in order to facilitate and attune to the different people they encounter through their work; often preferring to refer to their collaborators as 'people with complex communication needs' rather than people with learning disabilities. Their techniques of listening involve considerable time together and a body of expertise about the way in which particular art materials can help or hinder meaningful engagement. In the subsequent sections we discuss some of these practices in more depth.

\section{Constructing Conducive Spaces for Listening}

The Rocket artists meet weekly to make art at a studio in the Pheonix centre in Brighton, England. This bustling professional studio space contrasts with day centre arts environments, and AF feels this is an important space in which to help the Rockets develop their identity as artists and feel their work is valued. How the studio space is set up is considered important for facilitating a high quality session in which everyone feels meaningfully involved. Sometimes the work that is made is performative and collaborative (involving both collective visual art and dancemovement techniques) and sometimes it is more individual in nature. 


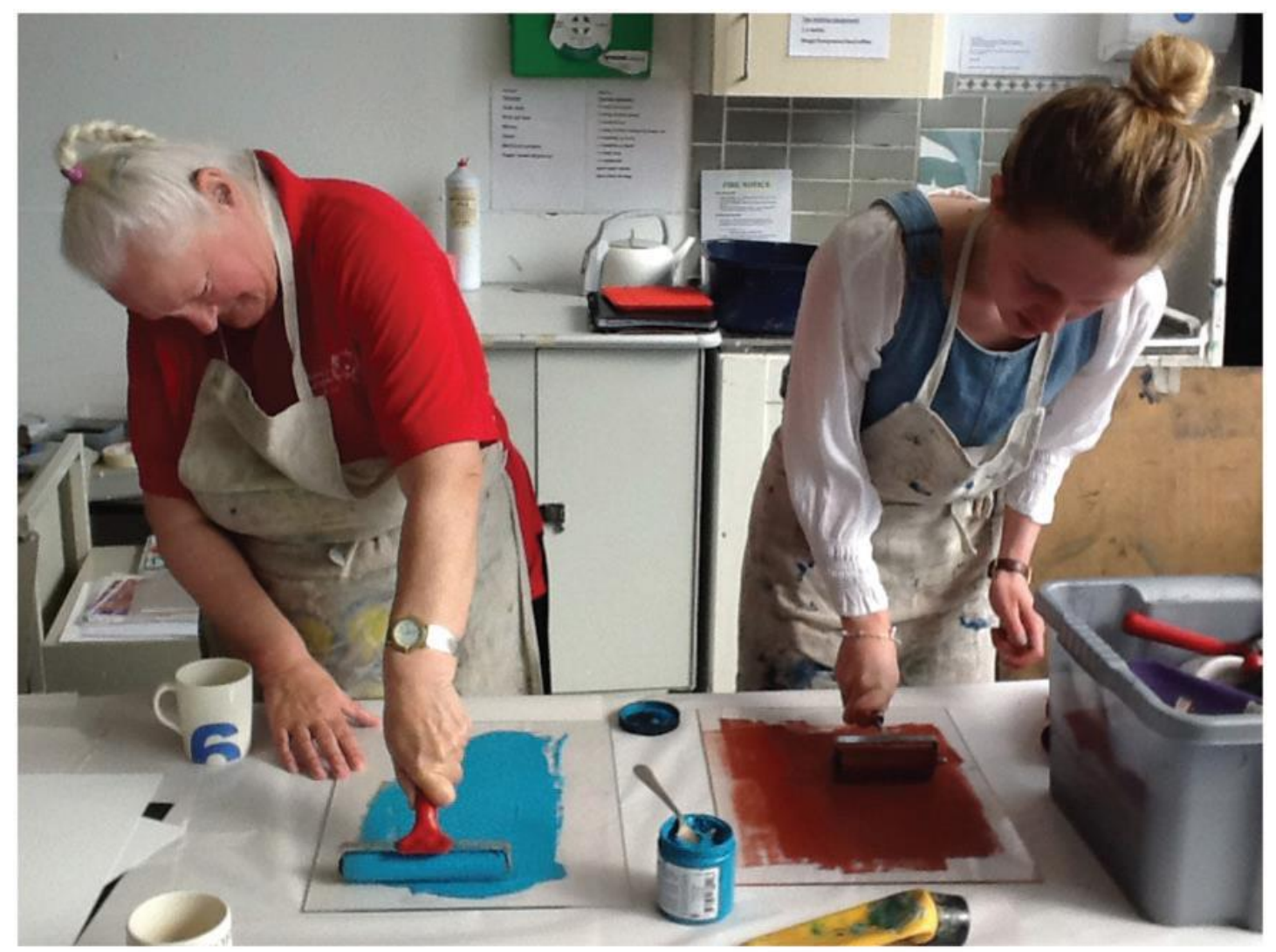

Figure 1. A member of the Rockets works alongside a student of Inclusive arts practice (Photo credit: Joanna Offer).

The Masters in Inclusive arts students who work alongside the Rockets learn how to construct the studio space in a way that makes it a conducive environment for listening and facilitating what AF refers to as 'meaningful artwork'. For AF meaningful artwork is work that speaks in some way by reaching someone other than the maker of that work. Setting up the studio to facilitate this sort of work may involve presenting participants with only a limited range of materials to work with so that they are not disabled by choice. Or this may involve starting by working only with the participants themselves and the space of the room so that they can work with feeling comfortable in each other's presence and comfortable with the space of the room before bringing in anything else to the communicative scene. For example, drama techniques could be used to learn each others name with an accompanying 
action and then participants might use movements to explore the texture and feel of the room.

Constructing a conducive space for listening may also involve catering to particular individual ways of being so that everyone can feel as comfortable as possible in the room (or even outside the room). For example, one person AF used to work with who had autism could only work alongside a fridge due to its reassuring hum and presence. So a fridge was brought into the art room so they could be enabled to participate in arts activities as well as through their own particular practice of fridgelistening/feeling. In this way Inclusive art practioners think quite broadly about what is in the room to enable people to listen and be listened to. Another example is a person who could only begin to work with the Rockets by standing outside the door and looking through the window. The group had to find creative ways for that person to be included by using the window - this involved a form of listening to someone who is physically far from you. As AF states,

"Some people don't want to be close to the group. So how do you listen to people who are doing that? I suppose first of all you need to recognize what they are doing and then you need to work on communicating with them. That might initially involve a long distance catching their eye. Then going out into the corridor with things so they feel involved and finding other creative ways of working alongside someone. Because what really strikes me is that those people who are spatially on the edges of what we do, really aren't on the edges of what we do. They are still there. If they wanted to leave they would be down the corridor and gone, but they don't leave they want to participate but on their own terms. So it is about providing opportunities to listen to 
them even though they are not in the room and opportunities to meet them through materials and practices. From catching their eyes to bringing objects out into the corridor."

Sometimes being in the studio space together won't involve much active verbal listening at all. Rather once the materials are in place there may be a session where we are all just making art together absorbed in the process of working with various art materials and feeling in-relation to them (as much as each other) through the absorbed doing of art. This sort of listening involves a coming about through the making of art together and selecting materials that listen - points we explore in the following section.

\section{Materials that listen}

The work of Inclusive arts practitioners sometimes involves sitting quietly with a person, speaking very little but choosing particular materials which help a person feel listened to or that help that person speak through an art work. AF explains how this involves selecting 'materials that listen'. As she puts it,

"For a material to support someone to express something it needs to be fluid, it needs to be changeable and moveable so you can play with it and apply it. So in granite where once you have made a mark it is very hard to change and you aren't able to craft it and manipulate it into saying what you want to say, unless you are very strong and adept at carving. Whereas you take a material like clay which is more fluid and you can literally impress upon it, this means you can articulate and re-articulate 
something. So the process of working with clay means it is potentially easier to say what you are wanting to say."

AF helps the Rockets express themselves by choosing materials that are mallable. This differs somewhat from the practice of an art therapist. For while an art therapist maybe interested in using clay or paint to help someone with emotional containment, self-expression or destructive urges (Chambala 2008) an Inclusive artist is also interested in developing the skills of that person to make something that might ultimately speak to a wider audience than just the maker and the facilitator. For AF the rationale for this practice is that by focusing primarily on the productive potential of the art rather than on an individual with a perceived problem the art-making comes into the foreground and often the 'problem' slips away. In this way art making and the listening process itself is what is transformational. However this also requires the Inclusive artists to support the person to develop the necessary skill set so that others can 'hear' them visually and so that ultimately a wider audience can appreciate their work. As AF proceeded to state,

“....in order to use materials effectively for them to say what you want them to say you need certain skills. So with paint you need to know that you need to wash your brush otherwise everything will become brown - the material will decide that everything is brown so then it won't be saying what you want it to say. With paint you also need to know how to mix colours so that the paint can say what you want it to say. Someone-else's version of blue isn't precise enough for ownership and you can see that straight away when an artwork is made straight from pots of colour - they 
look very childlike and it is hard to see the person within it because you just see the basic colors."

This is an important point because it involves a recognition that voice maybe lost through inappropriately facilitated arts activities. Furthermore, it is not necessarily just the person who is doing the speaking when we aim to enable voice through arts activities. In this example the material paint speaks and has a tendency to say 'brown'! Anyone with a basic knowledge of paint is likely to be able to 'listen out' for this feature of an artwork and perhaps see that it is the material more than the person who is speaking at that point. So AF proceeds to explain that the choice of material is very important,

"Materials which listen best are things like charcoal, chalk and pastel - things which are mallable like clay or which can be moved around the page, can be rubbed on, rubbed off and worked on top of. Some forms of print making also really work because it can enable a repeat that can enable a voice to be louder. Screen printing is a bit too tight and process heavy, but mono-printing works really well because you can work into the plate and change things, take things on and off." 


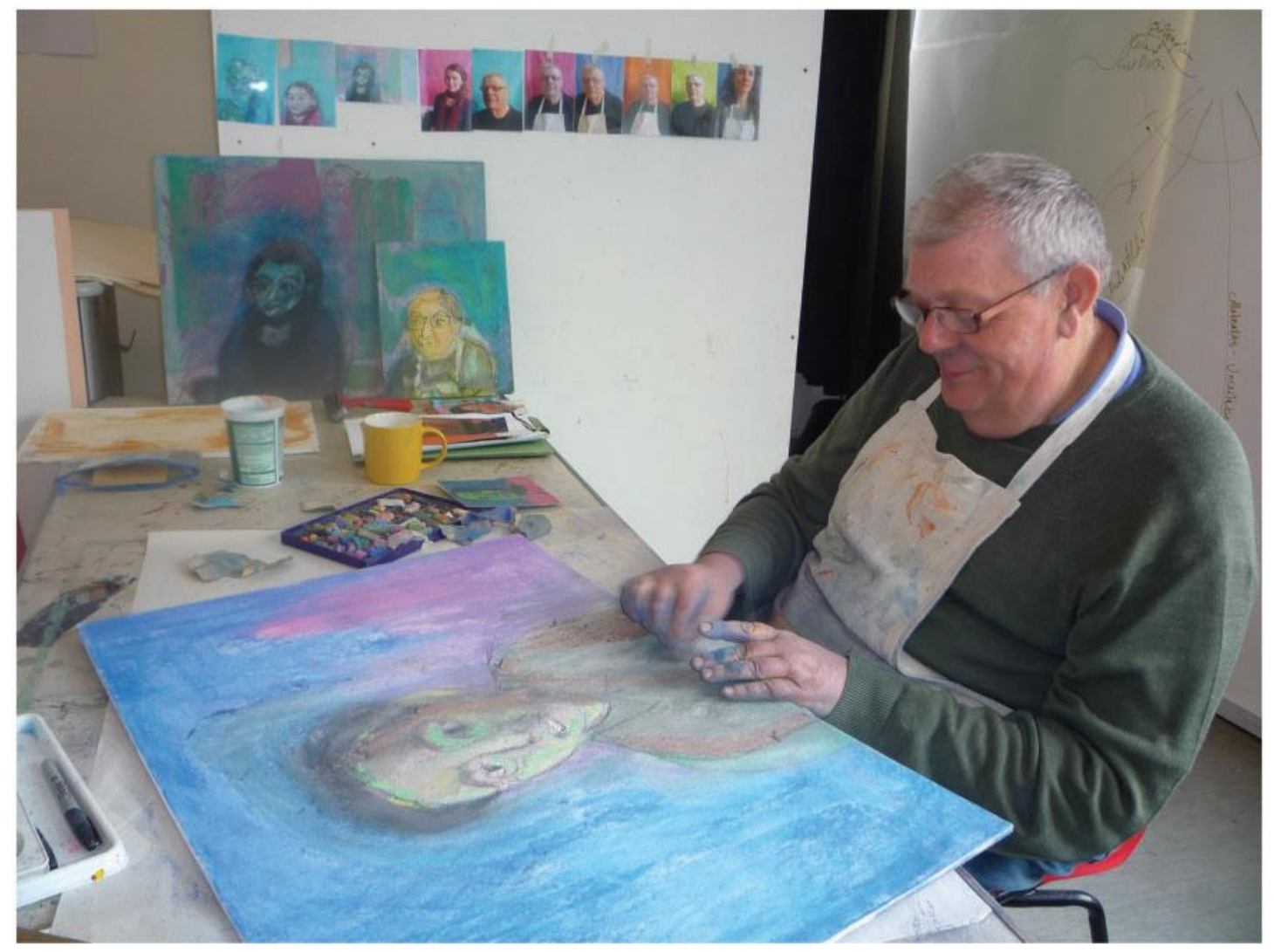

Figure 2. Mallable materials: a member of the Rockets works with pastel

Thus through our observations in the studio and our reflective conversations we began to realise the importance of materials in the process of facilitating voice. Some materials were more mallable than others and thus seemed to listen to the person better than others. For example the Rockets successfully work with pastels because they can be worked into to help them get the output they want (See figure 2). Certain materials also seemed to support people to be 'louder' - in the sense that their work is more likely to be looked at in a studio, gallery or other public space through the use of interesting materials, bold marks or repetition (Figures 3 and 4). For example,

"You might be working with someone who tends to have a very quiet voice, either a verbally quiet voice or a visually quiet voice. So they might be someone who does 
very small and light movements on a piece of paper and sometimes that comes from a very timid approach (often to living in all aspects). Now if someone who does that has a very hard thin pencil they are going to create a very small thin drawing, now that does have a beauty in itself. But if we were wanting to support people to be louder and help them be listened to we might give them a large brush so that then their movement results in a much bolder mark. So what that material has done is help to amplify what they are trying to communicate and sometimes surprise the person who is doing it. You still have that quietness behind it because the mark is light and soft but that picture is easier to look at and to read because it is more present. So it gives that person an opportunity to be more present ...this can result in a real confidence building delight and sense of achievement. It is bold enough to be received, listened to and commented on."

In short, the art materials and techniques matter. They affect the voice that can be heard through an artwork and they can affect what new forms of agency and subjecthood are brought into being. This raises further questions about how the work is then encountered by a wider audience (a topic we will addressing in another paper). It also requires an acknowledgement that materials not only support someone to express themselves, they are actively involved in that person's ongoing transformation. For example, in figure three paint brushes have been extended by using long canes. As AF has explained above this use of a bigger brush can help encourage people to be louder and bolder in their art work. AF has observed that this in turn can affect their confidence, making them bolder as a person. 


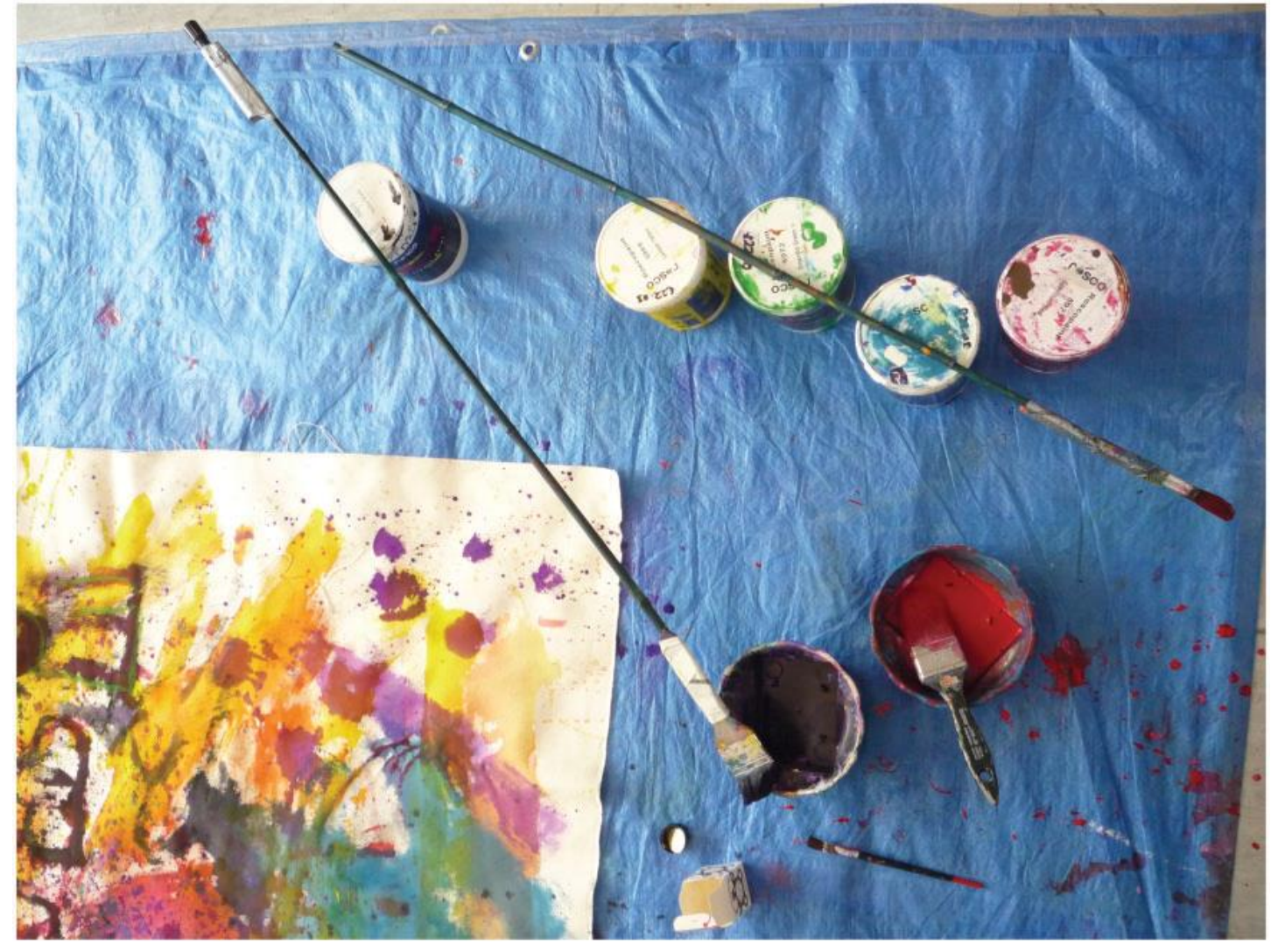

Figure 3. Big bold brushes 


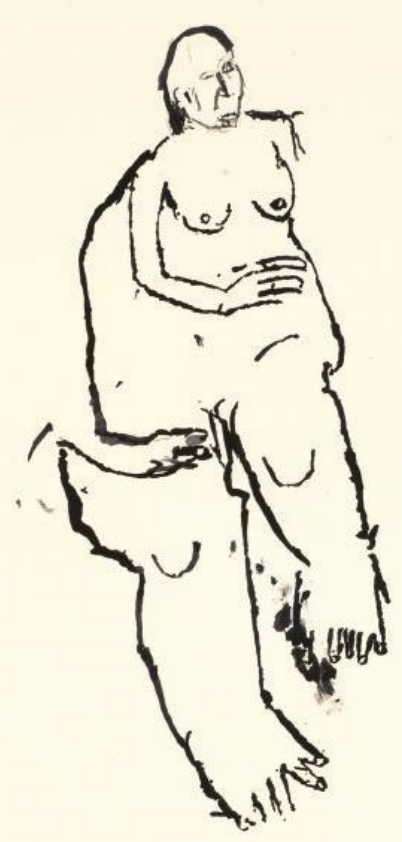

Figure 4. Loud drawing by a member of the Rockets (pen and ink)

\section{Materials as meeting points}

The previous section began to show how certain sorts of art materials are particularly good at listening and enabling individuals to have a voice. In this section we show how some art materials used in collaboration can also offer a 'meeting point' between people, enabling a form of visual or gestural conversation to take place that could not have taken place verbally. This sort of work is pictured in Figures 5 and 6, where two people work together or take turns on the same canvas or drawing. AF states about the drawings pictured here that, 
"This gives you a language and a place not to be alone through the material. This is brilliant because if somebody doesn't speak very much how else can you meet them? Particular art materials and other creative practices like call and response music or dance duets can do this. And the things that you have communicated with each other can be very intense but very hard to translate into another language. So for example if you have had a visual conversation with someone in pastels you have had a very intense communication period, something you have shared together which lives on in the material. You and that person can look at that drawing and understand that you have got something together now and that you have a shared memory and experience where you weren't alone. You were intensely with that person through that drawing. This is a great thing about collaborative practice because you can really get to know someone with a learning disability in an intense, proximate way. I don't know how you would do without that collaborative practice....You could all be in the same art studio and feeling very isolated and on your own but collaborative practice helps overcome that by finding ways to be with people through the materials...I think that form of collaboration is what the Rockets really love."

For AF, this act of two-way visual communication helps to extend the time you can be in the company of members of the Rockets in a mutually meaningful manner. Each person in the collaborative relationship can feel listened to and understood through their mark making. While there have been critiques regarding how feelings of togetherness and belonging through collaborative arts practices might translate into wider social inclusion agendas (Belfiore 2002; Hall 2013; Parr 2006). We think that the experience of such collaborative arts activities remains significant, for by facilitating a dialogue they allow for a temporary 'plane of equality' to be found (cf. 
Ranciere 2004). However, getting to know when such a 'plane of equality' is reached requires extended periods of time together. A topic elaborated on in the next section.

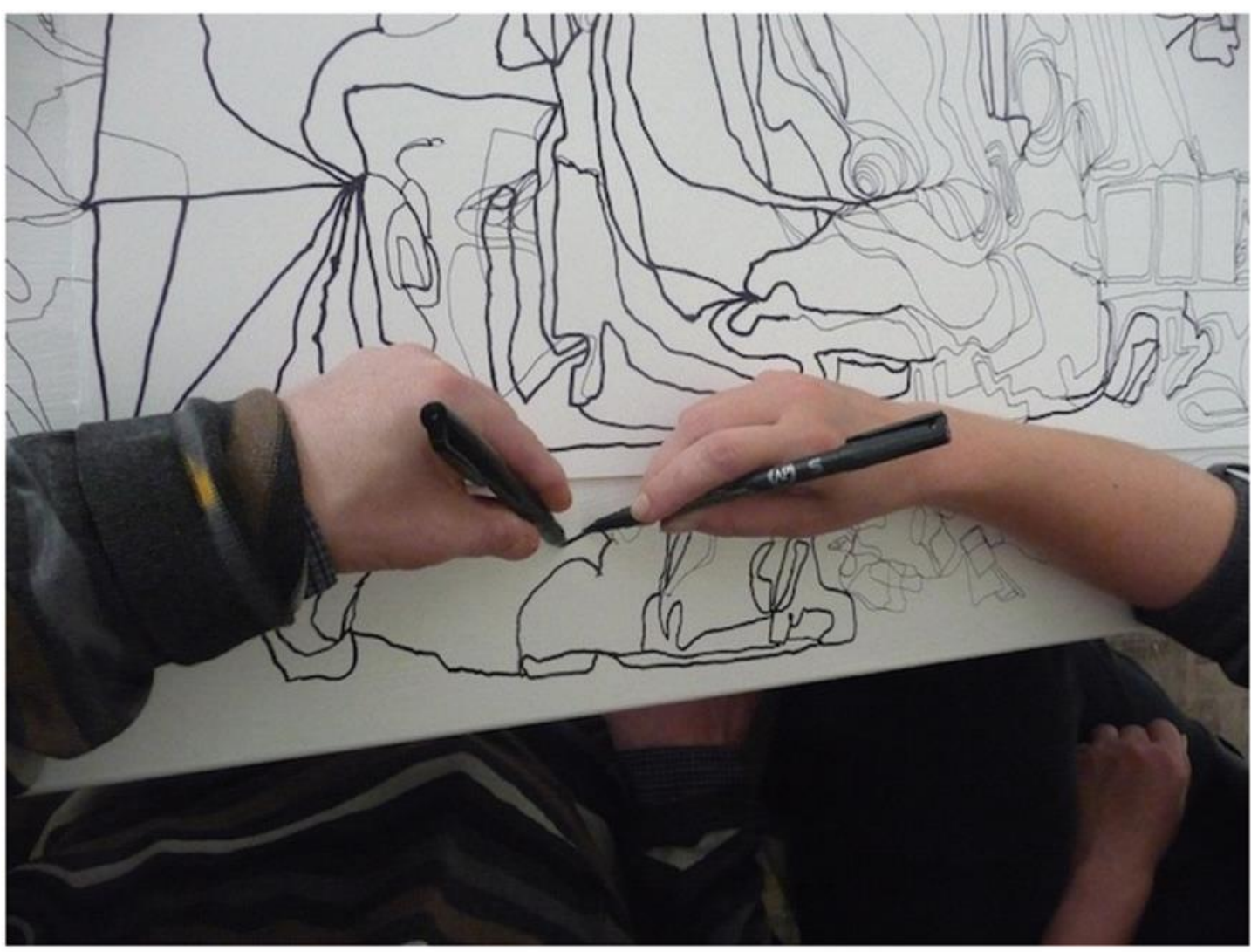

Figure 5. Collaborative drawing: a dialog between a member of the Rockets and a Masters student 


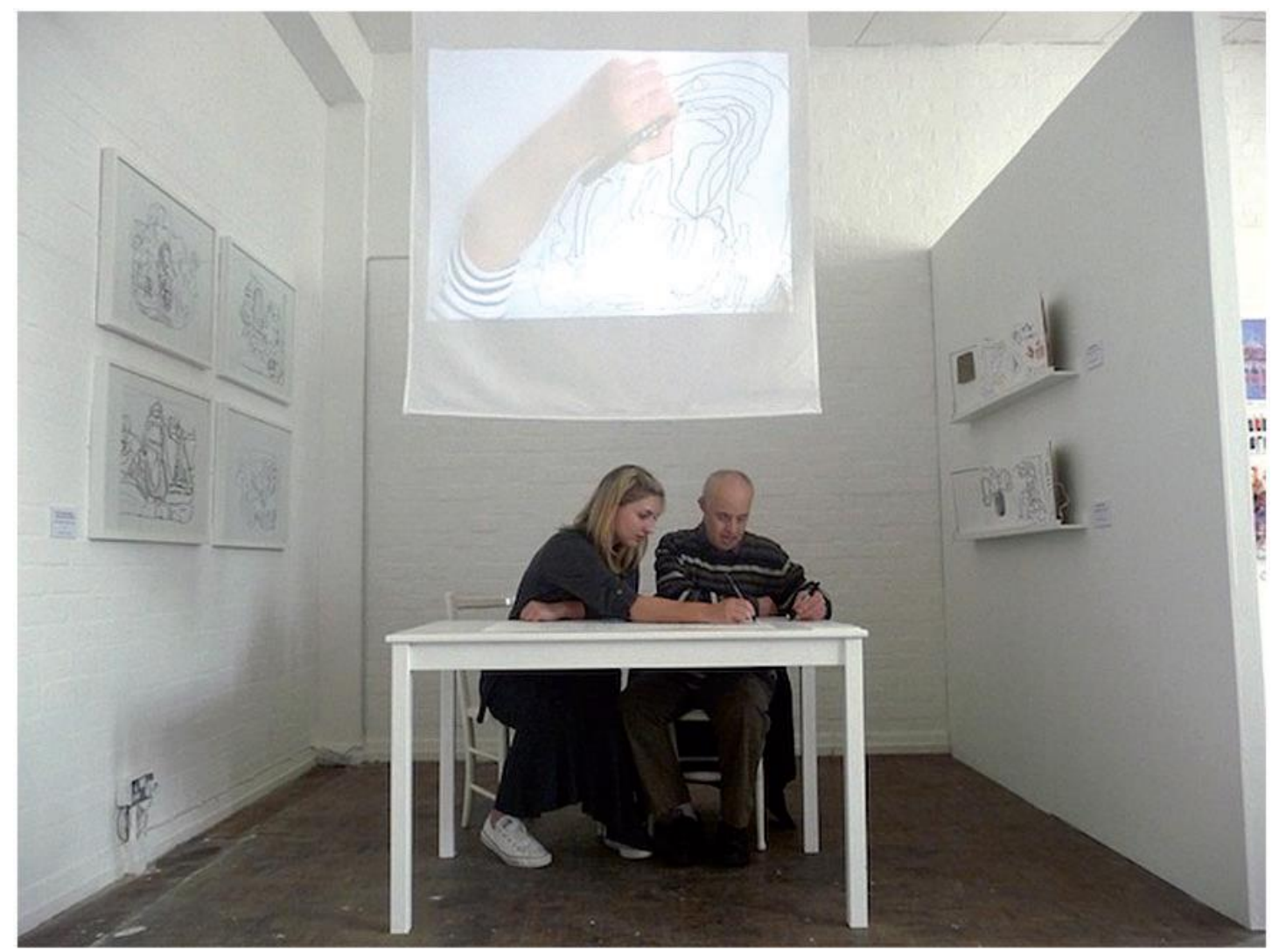

Figure 6. Collaborative drawing (Photo Courtesy of Jane Fox)

\section{Cliché, repetition, fear and absence in visual artworks}

To really listen and to hear what someone is saying visually and/or gesturally may require spending significant amounts of time together (in the case of $\mathrm{AF}$ and the Rockets weekly over a twelve year period). Just like spoken language, artworks can be full of cliché, repetition, fear and significant absences. For example, during another arts based research project $\mathrm{H}$ had worked on she had noticed one participant with autism kept on drawing cartoon characters (particularly when he was nervous or did not know what to do next). Rather than these being forms of expression for an audience these seemed to be a retreat from the overwhelming demands of the room and a form of personal world making. HM put this example to AF and asked her if members of the Rockets had any comparable visual vocabularies, 
"When Shirley is feeling a bit anxious about an activity we have offered she will often draw an owl. It is like a cartoon owl and it is like this default visual. If it was a conversation it would be a bit like a cliché - like a set phrase that people use in conversation so if I say 'it is a nice day isn't it' you will say 'oh yes lovely'. Well I think some people have a set visual response which is similar - what they have to do first before they feel confident enough to give something new and to give something more of themselves. This is what I have called the 'safety drawing'. I know if Shirley draws her owl there is a problem, but if you don't know her and haven't spent time with her you wouldn't realize that.... it took Shirley a year to not draw owls with us. You need time together to recognize things like that." 


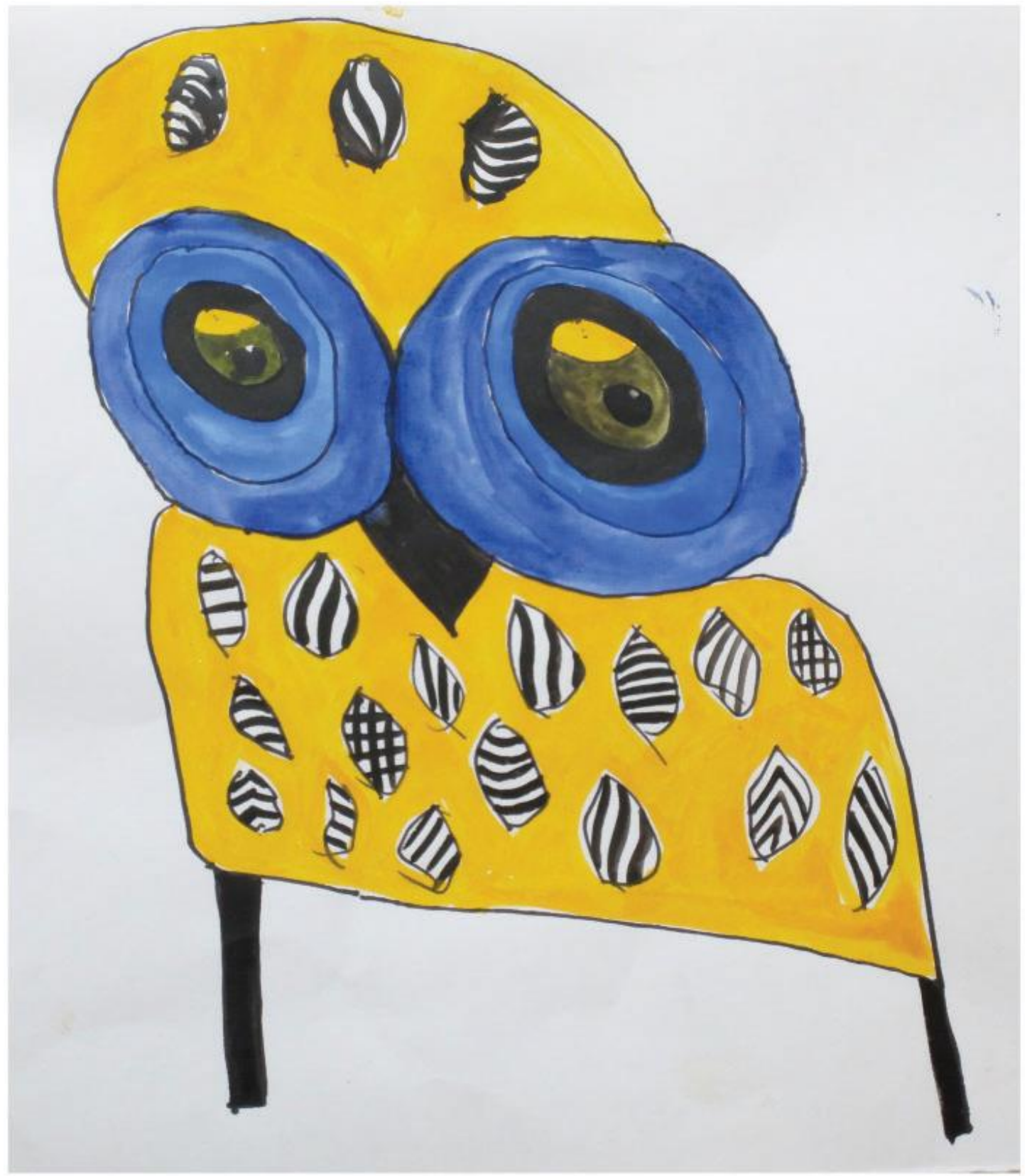

Figure 7. Shirley's Owls

It takes time to recognize that someone is doing what AF refers to as their 'safety drawings'. We explored some of the listening techniques she has used with the Rockets to try to help them move on when they get stuck in these forms of visual expression. These techniques included cultivating a non-judgmental atmosphere in the studio, keeping work safe, putting it away if they don't want others to look at it and starting with something they know about in order to help them express themselves 
visually. So for example with Shirley you might give her some other birds to draw to create links to what she feels comfortable with. Here artful listening in the studio involves attentiveness to both the visual language of the artwork being produced and an attunement to the body language (eye movements and gestures) of the people you are working with. As AF explains,

"Another member of the Rockets $95 \%$ of what he says is yes and then occasionally he will come up behind you and whisper something in your ear. A whole sentence which is completely gob smacking. But once you spend time with him and get to know him he has yes's that are no's. So he will be saying yes but you can see in his eyes it is a no."

This careful attunement to the body language of individual members of the Rockets involves time together. Their body language is not necessarily comparable to the sort of normative body language you might read about in psychology text books or take for granted in everyday life. There is no hasty way to come to know each other. Rather getting to know each other takes time and requires a form of "whole body listening' that is about recognising total communication and response (gestural, material and embodied), which understands it will generate (rather than just uncover) ideas and which understands the subject who is being listened to as always in process - 'being-with' both the art materials and others in the room. Such practices require an acceptance of a slow temporality and a non-individuated vocality. A form of slow artful hospitality for a hasty temporality can undermine the voice of people with learning disabilities and result in the sort of cliché and repetition mentioned at the start of this section. 


\section{Discussion: subjectivity in art-based encounters}

Through exploring how AF sets up the studio space, chooses 'materials that listen' and uses forms of collaborative drawing to meet people we have begun to show some of the ways in which Inclusive artists produce a listening space that attempts to accommodate a range of communicative styles (visual, verbal and gestural). In order for this listening space to be progressive and transformative (rather than repetitive and full of cliché) trusting and attuned relationships need to be established. This is comparable to research findings on 'trust and risk' in drama education (Nicholson 2002). Once such relationships are established then this artful listening not only enables voice, it brings into being certain forms of subjectivity that would not otherwise have existed. In this way well facilitated arts activities can produce a sense of selfhood and agency for people with learning disabilities who are often unused to be listened to. This is an important point to understand for researchers who are interested in using art based methods. There is no already constituted self-aware stable human subject whose voice is simply 'uncovered' through the use of an art activity. Rather, researchers attempting to utilize or interpret the results of art activities need to understand that the art materials themselves and the human participants influence each other in reciprocal ways.

These observations point us toward a distributed understanding of the human subject in arts based encounters who is partly formed in relation to the art materials they work with. Furthermore, the art materials and tools could also be understood as other actors in the communicative scene that need to be listened out for. Put simply, paint is likely to say brown and an HB pencil may not speak loud enough to be heard! Thus working with artists and art materials in a studio enables a voice (or a collective 
voice) to come into being that is characterized by the properties of the materials, tools and the setting as well as the individual who is making the art.

The dialogue, questions and outcomes that are involved in these artistic listening processes cannot be preempted. Rather working alongside the Rockets in an effective listening manner, requires an acceptance to journey creatively together to an unknown destination. For example, producing a collaborative drawing requires the partners in this process to work with each other and the material responding creatively to each other's moves and that of the material. Each person listens to each other through their use of the material. This involves a temporal unfolding -moving in and out of selfawareness - being with each other and being with the material. It is a form of listening as 'being with' that exists at the edges of signification. Artful listening in this context often means being patient, suspending a sense of 'time as pressing' in order to be open to the temporality of the other. This confirms the utility of philosopher Nancy's (2007) understanding of listening as a mode of 'coming about' and 'being-with' (cf Simpson 2009). For this is a mode of listening that can create new possible worlds which would not have otherwise existed. It is a mode of listening that some social researchers who are used to planning their encounter and its likely outcomes may feel uncomfortable entering into.

These observations are also significant for understandings of 'learning disability'. In fact well facilitated art activities enable people categorized as having a learning disability to move away from the deficit logic inherent in the category, at least temporarily, and be positively valued as artists - respected for their particular ways of doing, moving, being and seeing. In these contexts 'learning disability' becomes an 
uncertain and contestable category of being human that at times has no utility (cf. Goodley and Roets 2008). We don't wish to overstate the potential of these artful moments of 'doing, moving, being and seeing together' but they do provide some space in which trust can be built, established patterns of relating to other people challenged and new identities can be carved out as artists.

Some of the images of the work that is produced through these processes the reader may find ambiguous or hard to read. They are not 'about' or 'of' any single thing. The images require further input from the viewer. Some researchers might feel such ambiguous collective work does not 'give voice' in the forms that they are expecting even when such work has a more guided research driven direction to it. However, Anthropologist Erlmann (2005) discusses the value of such ambiguous unscripted moments of communication, for such moments disrupt a concept of communication as instrument or goal directed technique, and point towards a 'perisemiotic' state (Erlmann 2005, p19). This is a state that is less codifiable and thus offers a degree protection from the interpellatory power of discursive forces. Such a state has been identified as particularly important for marginalized groups who seek voice (Butler 1997). Furthermore for people with learning disabilities some of whom are nonverbal, such a creative, open communicative space is important, some would argue vital, for their meaningful existence - allowing for sustained shared communication and modes of being together.

\section{Conclusions: an expanded sense of listening}

Listening in geographical research has come a long way from the classic idea in linguistics that assumed an active speaker and a passive listener (Althusser 1977). 
Instead the communicative scene has become a complex arena of research where we need to acknowledge the role of the listener in constructing what can be heard, the possibility that materials themselves have a voice and the role that materials have in shaping the voices of people.

In this paper we set out to explore the embodied and material geographies of listening through creative visual arts activities with people with learning disabilities. Through a series of reflections on AF's Inclusive arts practice with the Rockets we hope to have shown you an expanded sense of listening through some examples of the ways in which Inclusive artists and their materials 'listen'. We highlighted the way in which appropriate spaces, attuned collaborators and mallable materials are required in order to listen well and facilitate voice effectively through art activities. We also found that while collaborative drawing may help foster a visual dialogue between two people, bringing new forms of agency into being, other repetitive drawing might be used as a safety net and form of personal world making, hindering rather than facilitating the listening process. These findings have implications for understandings of subjectivity in arts based research (discussed above), implications for social scientific understandings of the practice of listening and implications for the significance of art activities in people with learning disabilities lives.

Firstly, listening in research not only involves paying attention with the ear to that which is said, but rather listening also involves attuning oneself to all the possible verbal, visual and gestural vocabularies that a person might communicate in. Art making is important because it can allow for a greater level of acceptance of 'communicative distinctiveness' than talk alone. We hope the examples above have 
begun to show how certain voices do not come into being unless we construct spaces for artful listening that are conducive to hearing what is said or presented.

Furthermore, inclusive, artful listening is a skill and body of expertise that researchers should not underestimate. Understanding the alternative vocabularies, tactile knowledge and visual grammars that art based interactions create with people takes time and it is important to understand that particular choices around materials and activities bring into being different form of subjectivity. For example, visual and gestural vocabularies maybe facilitated more or less effectively depending on the choice of space, materials, tools and collaborators. Thus, as an increasing number of researchers (driven by impact and/or theoretically inclined research agendas) turn to art based methods and forms of research communication there needs to be an attentiveness to who is doing the facilitation, their capacity to attune to the people and materials in the room and what particular materials 'do' to the voices of participants.

Secondly, whole body artful listening, which attends to visual, verbal and gestural communication can make a tangible difference to the lives of people with learning disabilities. It often means being patient, suspending a sense of 'time as pressing' and accepting a non-individuated vocality in order to be open to the temporality and voice of the other and the group. It could be argued that this style of listening is antithetical to many of the key drives of the neo-liberal subject (Couldry 2010). It also requires a good knowledge of materials and processes that can facilitate voice and yield to the capacities of participants. For example, choosing a long brush can help someone make bolder marks and thus help someone feel bolder in them selves. By giving them the confidence to make choices and speak out in situations more than they otherwise would have done such activities can enable what AF refers to as 'everyday epic' 
moments; such as a verbal response rather than a nod, a movement towards the group rather than away from it, offering an opinion or making a cup of tea. For people whose lives tend to be characterised by a high degree of compliance with other's goals and agendas such 'everyday epic' moments are extremely significant. Further research, is required to explore in more depth what making art can achieve in the lives of people with learning disabilities beyond the art room and what audiences who encounter the outputs of this work make of it. Arts activities alone cannot achieve a better world for people with learning disabilities. However, careful listening through art making can create new possible worlds - where one person can meet another through a material, be listened to and both transform (ever so slightly) through that process.

\section{References}

Abell, S. et al. (2007) "Including everyone in research: The Burton Street Group" British Journal of Learning Disabilities 35, 121-24

Adams M. (2013) "Voicelessness" in Encyclopedia of Critical Psychology Eds Teo T. (Springer Reference, Berlin)

Aldridge, J. (2007) "Picture this: the use of participatory photographic research methods with people with learning disabilities" Disability \& Society 22(1), 1-17.

Althusser, L. (1977) Lenin and Philosophy, and other Essays, translated by Bewster B. (London, NLB) 
Anderson, B. (2002) “A Principle of Hope: Recorded Music, Listening Practices and the Immanence of Utopia" Geografiska Annaler B. 84, 211-227.

Anonymous (1998) People with learning difficulties share views on their involvement in a performing arts group, Community Work and Family, 1 (3), 329-334

Askins, K. and Pain, R. (2011) "Contact zones: participation, materiality, and the messiness of interaction" Environment and Planning D: Society and Space 29(5) 803821

Back, L. (2003) Deep listening: Researching music and the cartographies of sound. in Cultural Geography in Practice Eds Blunt A, Gruffud P, May J, Ogborn M, Pinder D (London, Arnold) $272-285$

Barrett, E and Bolt, B (2013) Carnal Knowledge: Towards a. 'New Materialism' through the arts, I.B. Tauris, London,

Baxter, J. and Eyles, J. (1997) Evaluating qualitative research in social geography: establishing 'rigour' in interview analysis. Transactions of the Institute of British Geographers 22 p505-525

Belfiore, E . (2002) “Art as a means of alleviating social exclusion: does it really work? A critique of instrumental cultural policies and social impact studies in the UK" International Journal of Cultural Policy 8 (1) 91-106 
Bondi, L. (2003) "Empathy and identification: conceptual resources for feminist fieldwork" ACME: International Journal of Critical Geography 2 64-76

Boxall, K. and Ralph, S. (2009) "Research ethics and the use of visual images in research with people with intellectual disabilities" Journal of Intellectual and Developmental Disability 34 (1) 45-54

Brookes, I., Archibald, S., McInnes, K., Cross, B., Daniel, B., and Johnson, F. (2012). "Finding the Words to Work Together: Developing a Research Design to Explore Risk and Adult Protection in Co-Produced Research" British Journal of Learning Disabilities 40(2)143-151.

Butler, J. (2005) Giving an Account of Oneself (New York, Fordham University Press)

Carlson, L. (2010) The faces of intellectual disability: philosophical reflections, (Bloomington: Indiana University Press)

Chambala, A. (2008). "Anxiety and art therapy: Treatment in the public eye." Art Therapy 25(4) 187-189

Couldry, N. (2010) Why Voice Matters: Culture and Politics After Neoliberalism. (London, Sage) 
Crang, M. (2002) "Qualitative methods: the new orthodoxy ?" Progress in human geography 26 (5) 647-655

Crang, M. (2005) "Qualitative methods (part 3) there is nothing outside the text?" Progress in human geography $29225-233$

Erlmann, V. (2004) Hearing Cultures: Essays on sound, listening and modernity (Berg: Oxford)

Foster, K, and Lorimer, H (2007) "Some reflections on art-geography as collaboration” Cultural Geographies 14 425-432

Gauntlett, D. (2006) "Creative and visual methods for exploring identities - A conversation between David Gauntlett and Peter Holzwarth" Visual Studies 21 (1) 8291.

Gilbert, J. (2004) 'Signifying Nothing: 'Culture', 'Discourse' and the Sociality of Affect" Culture Machine 6 2-24

Goode, D. A. (1995) A world without words: The social construction of children born deaf and blind (Philadelphia, PA, Temple University Press)

Goodley D.A. \& Roets G. (2008) 'The (be)comings and goings of developmental disabilities: the cultural politics of 'impairment', Discourse: Studies in the Cultural Politics of Education 29 239-259 
Hall, E. (2013) "Making and gifting belonging: creative arts and people with learning disabilities" Environment and Planning A 45 (2) 244-262

Hall, E. (2011) "Shopping for support: personalisation and the new spaces and relations of commodified care for people with learning disabilities" Social and Cultural Geography 12 (6) 589-603

Harrison, P. (2007) “How shall I say it.?' Relating the nonrelational” Environment and Planning A 39 590-608

Hawkins, H. (2010) "The Argument of the Eye. Cultural Geographies of Installation Art." Cultural Geographies 17 (3) 1-19

Hawkins, H (2013) “Geography and Art, An Expanding Field: Site, the Body and Practice" Progress in Human Geography 37 (1) 52-71

Palmer (née Reiser) M, Jones O (2014) "On breathing and geography: explorations of data sonifications of timespace processes with illustrating examples from a tidally dynamic landscape (Severn Estuary, UK)" Environment and Planning A 46(1) 222 240

JCHR (2008) A life like any other? Human rights of adults with learning disabilities, Seventh Report of Session 2007-08, London, House of Lords/House of Commons, Joint Committee on Human Rights. 
http://www.publications.parliament.uk/pa/jt200708/jtselect/jtrights/40/40i.pdf (aceessed 4th February 2014)

Kiernan, C. (1999) "Participation in Research by People with Learning Difficulties: Origins and issues" British Journal of Learning Disabilities 27 (2) 43-47

Kanngieser, A. (2012) "A sonic geography of voice: Towards an affective politics" Progress in Human Geography 36 (3) 336-353

Laurier, E. \& Philo, C. (2006) "Cold shoulders and napkins handed: gestures of responsibility" Transactions of the Institute of British Geographers, 31 (2) 193-208

Leavy, P. (2009) Method Meets Art: Arts-Based Research Practice, Publisher: Guilford Press

Macpherson, H.M. and Bleasedale, B. (2012) "Journeys in ink: re-presenting the spaces of inclusive arts practice" Cultural Geograpies 19 (4) 523-534

Nancy, Jean-Luc, 2007 Listening (New York, Fordham University Press)

Nicholson, H. 2002 "Drama Education and the Politics of Trust" Research in Drama Education 7 (1) 81-93

Nind, M. (2008) Conducting qualitative research with people with learning, communication and other disabilities: Methodological challenges, ESRC National 
Centre for Research Methods Review Paper

Palmer (née Reiser) M, Jones O, 2014, "On breathing and geography: explorations of data sonifications of timespace processes with illustrating examples from a tidally dynamic landscape (Severn Estuary, UK)" Environment and Planning A 46(1) 222 240

Parr, H. (2006) "Mental health, the arts and belongings" Transactions of the Institute of British Geographers 31(2)150-166

Pratt, G. and Johnston, C. 2010 "Nanay (Mother): a testimonial play" Cultural Geographies 17, 123-133

Pratt. G. 2010 “Listening in spaces of ordinariness: Filipino-Canadian youths' transnational lives" Children's Geographies 8 (4) 343-352.

Radford, J. (1994) Intellectual Disability and the Heritage of Modernity, in Rioux, M. and Bach,M. (Eds) Disability Is Not Measles: New Research paradigms in Disability, North York Ontario, Roeher Institute.

Ranciere, J. (2009) Aesthetics and Its Discontents. Translated by Corcoran,S. Publisher, Polity, 2009.

Reynolds, F. (2002). "An exploratory survey of opportunities and barriers to creative leisure activity for people with learning disabilities." British Journal of Learning 
Disabilities 30(2): 63-67

Rose, G. (1997) "Situating knowledges: positionality, reflexivity and other tactics" Progress in Human Geography, 21: 305-20.

Tolia-Kelly, D.P. (2007) Participatory Art: Capturing Spatial Vocabularies in a Collaborative Visual Methodology with Melanie Carvalho and South Asian Women in London, UK in Participatory Action Research Approaches and Methods:

Connecting People, Participation and Place Eds Kindon, S., Pain, R. \& Kesby, M. (London, Routledge)

White, M. (2009). Arts development in community health: A social tonic. (Oxford, Radcliffe Publishing Ltd)

Worth, N. and Poynor (2011) Performer training: researching practice in the theatre laboratory in Research Methods in Theatre and Performance Eds Kershaw B. and Nicholson, H. (Edinburgh University Press: Edinburgh) 